\title{
Probing Ion Transfer across Liquid-Liquid Interfaces by Monitoring Collisions of Single Femtoliter Oil Droplets on Ultramicroelectrodes
}

Haiqiang Deng, ${ }^{1, \S}$ Jeffrey E. Dick, ${ }^{1, \S}$ Sina Kummer, ${ }^{2}$ Udo Kragl, ${ }^{2}$ Steven H. Strauss, ${ }^{3}$ and Allen J. Bard ${ }^{1 *}$

${ }^{1}$ Center for Electrochemistry, Department of Chemistry, The University of Texas at Austin, Austin, Texas 78712, United States

${ }^{2}$ Division of Analytical and Technical Chemistry, Institute of Chemistry, University of Rostock, D-18059

Rostock, Germany

${ }^{3}$ Department of Chemistry, Colorado State University, Fort Collins, Colorado 80523, United States

§Authors contributed equally to this work.

Table of Contents

Molecular Structures of Redox Probes (Figure S1)

Picture of the Toluene/Water Emulsions (Figure S2)

Conditions of Electrochemical Collision Experiments (Table S1)

Estimation of Collision Frequency, Size Distribution, and $i-t$ Behavior

Estimation of the Formal Ion transfer Potential at the o/w Interface

$\mathrm{CV}$ of $1 \mathrm{mM} \mathrm{FcMeOH}$ on the Pt UME in Aqueous (Figure S3)

$\mathrm{CV}$ of $2.5 \mathrm{mM}$ Rubrene $v s$. Ferrocene on the Pt UME in Toluene (Figure S4)

Estimation of Formal Redox Potential of Rubrene in Toluene vs. Aqueous SHE

$\mathrm{CV}$ of $15 \mathrm{mM}$ DEC on the Pt UME in Toluene and Amperometric $i-t$ Curves of Collisions of

Emulsion Droplets on Pt UME Biased at Different Potentials (Figure S5)

References

S-10 


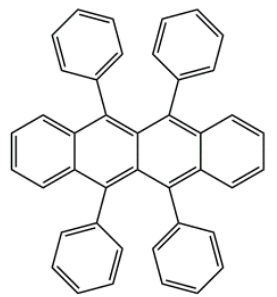

(A)

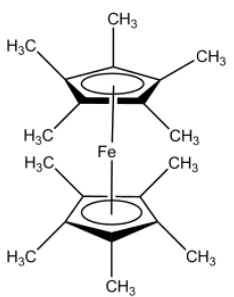

(B)

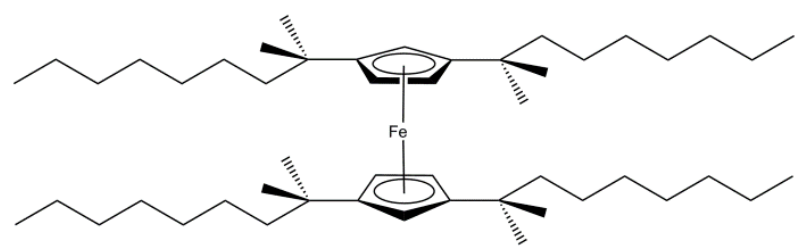

(C)

Figure S1. Molecular structure of (A) rubrene (R), (B) decamethylferrocene (DMFc), and (C) 1,1',3,3'-tetra(2methyl-2-nonyl)ferrocene (DEC).

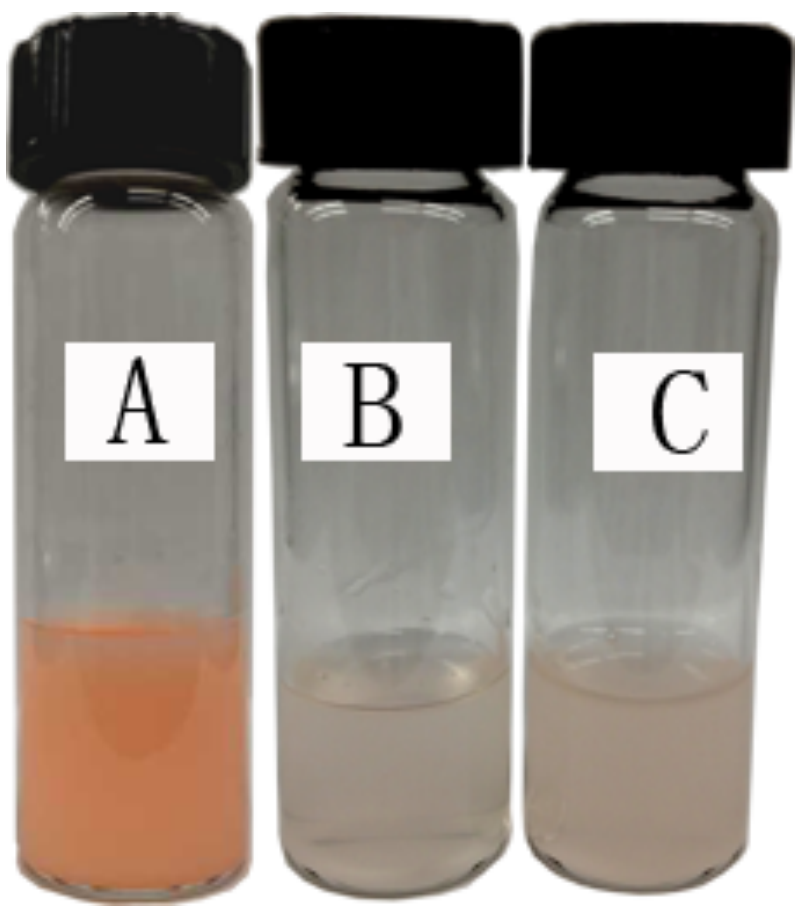

Figure S2. (A) The original toluene (5 mM rubrene $+400 \mathrm{mM}$ IL-PA)/water emulsion with the droplet concentration in $87.12 \mathrm{pM}$. (B) The toluene ( $5 \mathrm{mM}$ rubrene $+400 \mathrm{mM}$ IL-PA)/water emulsion with the droplet concentration in $3.35 \mathrm{pM}$ (i.e. diluted 26 times from the original emulsion). (C) The same amount of toluene droplets as in B but in $5 \mathrm{mM} \mathrm{NaTPB}$ aqueous continuous phase.

Table S1. Summary of the electrochemical collision experiments employing toluene (rubrene + IL-PA)/water emulsions with/without additional ions in o/w phases.

\begin{tabular}{ccc}
\hline Salt & Dissolved in & EDR \\
\hline No salt control & Water and toluene & No \\
$5 \mathrm{mM} \mathrm{NaOH}$ & Water & No
\end{tabular}




$\begin{array}{ccc}5 \mathrm{mM} \mathrm{TBAOTf} & \text { Toluene } & \text { Yes } \\ 5 \mathrm{mM} \mathrm{THAPF}_{6} & \text { Toluene } & \text { Yes } \\ 5 \mathrm{mM} \mathrm{TBAClO}_{4} & \text { Water } & \text { Yes } \\ 5 \mathrm{mM} \mathrm{NaTPB} & \text { Water } & \text { Yes }\end{array}$

\section{Estimation of Collision Frequency, Size Distribution, and $i-t$ Behavior}

The diffusion coefficient of an emulsion droplet $\left(D_{\text {ems }}\right)$ can be estimated by the StokesEinstein relation shown in equation SI 1,

$$
D_{\text {ems }}=\frac{k_{\mathrm{B}} T}{6 \pi \eta r_{\mathrm{ems}}}
$$

where $k_{\mathrm{B}}$ is the Boltzmann constant, $T$ is the thermodynamic temperature, $\eta$ is the dynamic viscosity of water at $298.15 \mathrm{~K}$, and $r_{\mathrm{ems}}$ is the radius of an emulsion droplet that can be obtained from dynamic light scattering (DLS) or the integrated current in the EDR measurement, as discussed in the following. The collision frequency of the emulsion droplet ( $\left.f_{\text {ems }}\right)$ dictated by mass transfer by diffusion to the electrode surface can be calculated by equation SI $2{ }^{1}$

$$
f_{\text {ems }}=4 D_{\text {ems }} c_{\text {ems }} r_{\mathrm{UME}} N_{\mathrm{A}}
$$

where $c_{\mathrm{ems}}$ is the concentration of emulsion droplets, $r_{\mathrm{UME}}$ is the radius of the UME, and $N_{\mathrm{A}}$ is Avogadro's number.

The current transient in each spike during the $i-t$ measurement can be integrated to obtain the charge for electrolysis of the redox species in a single emulsion droplet. In accords with Faraday's law, the size of each emulsion droplet can be calculated according to equation SI 3, based on the assumption of complete electrolysis (i.e. bulk electrolysis) of analyte during a collision event. The droplet diameter $\left(d_{\text {drop }}\right)$ is expressed in equation SI 3 shown below,

$$
d_{\text {drop }}=\sqrt[3]{\frac{6 Q}{\pi n F c_{\text {redox }}}}
$$

where $Q$ is the charge integrated from the current spike versus time, $n$ is the number of electrons transferred per electron transfer (ET) event $(n=1$ in each case given within this report), $F$ is Faraday constant, and $c_{\text {redox }}$ is the redox species A's (see Figure 1) concentration in the dispersed droplet phase.

With regard to the $i-t$ behavior during bulk electrolysis at the potential held in the limiting current region, it has been shown in our previous work ${ }^{2-4}$ that the current decays exponentially with time, specified in equation SI 4,

$$
i(t)=i_{\mathrm{p}} \exp \left[-\left(\frac{m A}{V}\right) t\right]
$$

where $i(t)$ is the current at any time, $i_{\mathrm{p}}$ is the peak current of a spike, $m$ is the mass-transfer coefficient inside the droplet, $A$ is the contact area between the UME and the emulsion droplet 
calculated from the contact radius $r_{\mathrm{c}}$ between the UME and the emulsion droplet with the assumption of the contact geometry is a disk, $V$ is the volume of the droplet calculated from the diameter of the droplet $-d_{\text {drop }}$, and $t$ is the electrolysis time. $m\left(m=\frac{4 D_{\text {redox }}^{\circ}}{\pi r_{\mathrm{c}}}\right)$ is related to the diffusion coefficient of the redox probe in oil phase $\left(D_{\text {redox }}^{\circ}\right)$ that can be measured by equation SI 5 and CV in Figure 2A.

$$
D_{\text {redox }}^{\mathrm{o}}=\frac{i_{\mathrm{ss}}}{4 n F c_{\mathrm{redox}}^{\mathrm{o}, 0} r_{\mathrm{UME}}}
$$

where $i_{\mathrm{ss}}$ is the steady-state current at the Pt UME, $c_{\text {redox }}^{\mathrm{o}, 0}$ is the initial concentration of the redox probe $-\mathrm{A}$ in oil phase. All other parameters have been defined.

Substituting $m$ into equation SI 4, we achieve the current dependence on time in equation SI 6 , and equation SI 6 is used for fitting the experimental $i-t$ profile of each current spike with $r_{\mathrm{c}}$ as the single adjusting parameter.

$$
i(t)=i_{\mathrm{p}} \exp \left[-\left(\frac{4 r_{\mathrm{c}} D_{\text {redox }}^{\mathrm{o}}}{V}\right) t\right]
$$

\section{Estimation of the Formal Ion Transfer Potential at the o/w Interface}

As the current magnitude during collision is in the pA scale, ${ }^{2-4}$ the effect of $i R$ drop on the applied potential, either in emulsion oil droplets or in the continuous aqueous phase (even without any supporting electrolyte), is negligible. Provided that the ET at the UME/o ("o" = toluene) interface and ion transfer (IT) at the $\mathrm{o} / \mathrm{w}$ ("w" = aqueous) interface are both fast enough to establish the Nernstian equilibrium, the overall potential $E_{1}$ applied at the UME (for the process depicted in equation 1) is expressed as ${ }^{5}$

$$
E_{1}=\Delta_{\mathrm{o}}^{\mathrm{UME}} \phi+\Delta_{\mathrm{w}}^{\mathrm{o}} \phi+E_{\mathrm{ref} 1}^{\circ}
$$

where $E_{1}$ is split into three components: $\Delta_{\mathrm{o}}^{\mathrm{UME}} \phi$, the redox potential at the UME/o interface that is expressed in equation SI 8; $\Delta_{\mathrm{w}}^{\mathrm{o}} \phi$, the inner potential difference at the $\mathrm{o} / \mathrm{w}$ interface depicted in equation SI 9; $E_{\text {refl }}^{\circ}$, the reference electrode potential in the aqueous phase. It follows that

$$
\begin{aligned}
& \Delta_{\mathrm{o}}^{\mathrm{UME}} \phi=\Delta_{\mathrm{o}}^{\mathrm{UME}} \phi_{\mathrm{A}^{+} / \mathrm{A}}^{\mathrm{O}}+\frac{R T}{F} \ln \left(\frac{c_{\mathrm{A}^{+}}^{\mathrm{o}}}{c_{\mathrm{A}}^{\mathrm{o}}}\right) \\
& \Delta_{\mathrm{w}}^{\mathrm{o}} \phi=\Delta_{\mathrm{w}}^{\mathrm{o}} \phi_{\mathrm{X}^{+}}^{\circ}+\frac{R T}{F} \ln \left(\frac{c_{\mathrm{X}^{+}}^{\mathrm{w}}}{c_{\mathrm{X}^{+}}^{\mathrm{o}}}\right)
\end{aligned}
$$


where $\Delta_{\mathrm{o}}^{\mathrm{UME}} \phi_{\mathrm{A}^{+} / \mathrm{A}}^{\circ 1}$ is the formal potential of the redox couple $\mathrm{A}^{+} / \mathrm{A}, c_{\mathrm{A}^{+}}^{\mathrm{o}}$ and $c_{\mathrm{A}}^{\mathrm{o}}$ are the electrode surface concentrations of $\mathrm{A}^{+}$and $\mathrm{A}$, respectively, $\Delta_{\mathrm{w}}^{\mathrm{o}} \phi_{\mathrm{X}^{+}}^{\circ}$ is the formal transfer potential of $\mathrm{X}^{+}$across the $\mathrm{o} / \mathrm{w}$ interface, $c_{\mathrm{X}^{+}}^{\mathrm{w}}$ and $c_{\mathrm{X}^{+}}^{\mathrm{o}}$ are the $\mathrm{X}^{+}$concentrations in the aqueous and organic sides of the liquid/liquid interface, respectively, and $R$ is the universal gas constant. $c_{\mathrm{X}^{+}}^{\mathrm{o}}$ is assumed to be the same as the initial bulk value for a first approximation considering the high mass transfer effect in the femtoliter droplet. In sampled current voltammetry, ${ }^{6}$ equation SI 8 can be re-written in the form of equation SI 10

$$
\Delta_{\mathrm{o}}^{\mathrm{UME}} \phi=\Delta_{\mathrm{o}}^{\mathrm{UME}} \phi_{\mathrm{A}^{+} / \mathrm{A}}^{\circ}+\frac{R T}{F} \ln \left(\frac{D_{\mathrm{A}^{+}}^{\mathrm{o}}}{D_{\mathrm{A}}^{\mathrm{o}}}\right)+\frac{R T}{F} \ln \left(\frac{i_{\mathrm{d}}-i}{i}\right)
$$

where $D_{\mathrm{A}^{+}}^{\mathrm{o}}$ and $D_{\mathrm{A}}^{\mathrm{o}}\left(D_{\mathrm{A}}^{\mathrm{o}}=D_{\text {redox }}^{\mathrm{o}}\right)$ are the diffusion coefficients of the redox couple $\mathrm{A}^{+} / \mathrm{A}$ in the oil phase, $i_{\mathrm{d}}$ and $i$ are the anodic diffusion-limiting current and the sampled current at any potential that is deviated from the diffusion-limited values. As the overall process is an ET coupled with IT reaction, the sampled current flowing through the $\mathrm{o} / \mathrm{w}$ and UME/o interfaces is equal. Under the Cottrell experimental conditions, the diffusion-limited current as a function of time at the o/w and UME/o interfaces can be described in equations SI 11 and SI 12 , respectively ${ }^{5}$

$$
\begin{aligned}
& i_{\mathrm{d}(\mathrm{o} / \mathrm{w})}=F A_{\mathrm{o} / \mathrm{w}} \sqrt{\frac{D_{\mathrm{X}^{+}}^{\mathrm{w}}}{\pi \tau}} c_{\mathrm{X}^{+}}^{\mathrm{w}} \\
& i_{\mathrm{d}(\mathrm{UME} / \mathrm{o})}=F A_{\mathrm{UME} / \mathrm{o}} \sqrt{\frac{D_{\mathrm{A}}^{\mathrm{o}}}{\pi \tau}} c_{\mathrm{A}}^{\mathrm{o}, 0}
\end{aligned}
$$

where $A_{\mathrm{o} / \mathrm{w}}$ and $A_{\mathrm{UME} / \mathrm{o}}$ are the $\mathrm{o} / \mathrm{w}$ interfacial area and the UME/o interfacial area, respectively. $D_{\mathrm{X}^{+}}^{\mathrm{w}}$ is the diffusion coefficient of $\mathrm{X}^{+}$in aqueous phase, $c_{\mathrm{A}}^{\mathrm{o}, 0}\left(=c_{\text {redox }}^{\mathrm{o}, 0}\right)$ is the initial bulk concentration of $\mathrm{A}$ in oil phase, and $\tau$ is the sampling time for the sampledcurrent voltammetry. Due to electro-wetting of the electrolytic droplet on the electrified UME surface, ${ }^{7}$ the droplet geometry will likely deform from the perfect sphere. The ET coupled IT process is proposed to occur at the three-phase junction line where the UME, oil, and water meet, in accord with principle of the lowest energy. ${ }^{8}$ This one-dimensional molecularly-thin line provides all requirements for initiating the electrochemical reaction, i.e., the electron conductor, redox probe, and the necessary transferable ions. ${ }^{8}$ So $A_{\mathrm{o} / \mathrm{w}}$ and $A_{\mathrm{UME} / \mathrm{o}}$ are merged into the circumference of the contact disk between the droplet and the underlying UME. Therefore, $A_{\mathrm{o} / \mathrm{w}} / A_{\mathrm{UME} / \mathrm{o}}=1$. Accordingly, both $i_{\mathrm{d}(\mathrm{o} / \mathrm{w})}$ and $i_{\mathrm{d}(\mathrm{UME} / \mathrm{o})}$ are proportional to the contact radius, $r_{\mathrm{c}}\left(r_{\mathrm{c}}\right.$ has been detailed in equation SI 6). This is in good agreement with the results shown in Figures 4 and 5 , in which the peak current $\left(i_{\mathrm{p}}\right.$, which has been detailed in equation SI 6) of a spike in $i-t$ curve is in linear relation with the contact radius. 
Equating $i_{\mathrm{d}(\mathrm{o} / \mathrm{w})}$ and $i_{\mathrm{d}(\mathrm{UME} / \mathrm{o})}$, we obtain

$$
c_{\mathrm{X}^{+}}^{\mathrm{w}}=c_{\mathrm{A}}^{\mathrm{o}, 0} \sqrt{\frac{D_{\mathrm{A}}^{\mathrm{o}}}{D_{\mathrm{X}^{+}}^{\mathrm{w}}}}
$$

Substituting equations SI 9, SI 10, and SI 13 into equation SI 7, we obtain

$$
E_{1}=\Delta_{\mathrm{o}}^{\mathrm{UME}} \phi_{\mathrm{A}^{+} / \mathrm{A}}^{\circ}+\Delta_{\mathrm{w}}^{\mathrm{o}} \phi_{\mathrm{X}^{+}}^{\circ}+\frac{R T}{F} \ln \left(\frac{D_{\mathrm{A}^{+}}^{\mathrm{o}}}{D_{\mathrm{A}}^{\mathrm{o}}}\right)+\frac{R T}{F} \ln \left(\frac{i_{\mathrm{d}}-i}{i}\right)+\frac{R T}{F} \ln \left(\frac{c_{\mathrm{A}}^{\mathrm{o}, 0}}{c_{\mathrm{X}^{+}}^{\mathrm{o}}} \sqrt{\frac{D_{\mathrm{A}}^{\mathrm{o}}}{D_{\mathrm{X}^{+}}^{\mathrm{w}}}}\right)+E_{\mathrm{ref} 1}^{\circ}
$$

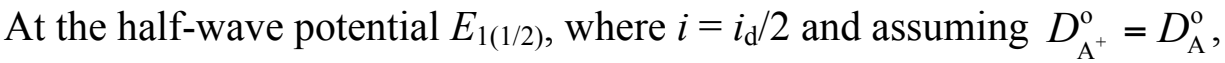

$$
E_{1(1 / 2)}=\Delta_{\mathrm{o}}^{\mathrm{UME}} \phi_{\mathrm{A}^{+} / \mathrm{A}}^{\circ}+\Delta_{\mathrm{w}}^{\mathrm{o}} \phi_{\mathrm{X}^{+}}^{\circ}+\frac{R T}{F} \ln \left(\frac{c_{\mathrm{A}}^{\mathrm{o}, 0}}{c_{\mathrm{X}^{+}}^{\mathrm{o}}} \sqrt{\frac{D_{\mathrm{A}}^{\mathrm{o}}}{D_{\mathrm{X}^{+}}^{\mathrm{w}}}}\right)+E_{\mathrm{ref} 1}^{\circ}
$$

If we only consider the redox reaction of $\mathrm{A}(\mathrm{o}) \leftrightarrow \mathrm{A}^{+}(\mathrm{o})+\mathrm{e}^{-}$at the UME in the bulk oil phase, the potential at the UME $E_{2}$ can be described in equation SI 16,

$$
E_{2}=\Delta_{\mathrm{o}}^{\mathrm{UME}} \phi_{\mathrm{A}^{+} / \mathrm{A}}^{\circ,}+\frac{R T}{F} \ln \left(\frac{c_{\mathrm{A}^{+}}^{\mathrm{o}}}{c_{\mathrm{A}}^{\mathrm{o}}}\right)+E_{\mathrm{ref} 2}^{\circ}
$$

Where $E_{\text {ref2 }}^{\circ}$ is the potential of the same reference electrode but in the bulk oil phase. At the half-wave potential $E_{2(1 / 2)}$, where $c_{\mathrm{A}^{+}}^{\mathrm{o}}=c_{\mathrm{A}}^{\mathrm{o}}$, equation SI 16 becomes

$$
E_{2(1 / 2)}=\Delta_{\mathrm{o}}^{\mathrm{UME}} \phi_{\mathrm{A}^{+} / \mathrm{A}}^{\circ 1}+E_{\mathrm{ref} 2}^{\circ}
$$

Subtracting equation SI 15 by equation SI 17, equation SI 18 is obtained,

$$
\Delta E_{1 / 2}=E_{1(1 / 2)}-E_{2(1 / 2)}=\Delta_{\mathrm{w}}^{\mathrm{o}} \phi_{\mathrm{X}^{+}}^{\circ}+\frac{R T}{F} \ln \left(\frac{c_{\mathrm{A}}^{\mathrm{o}, 0}}{c_{\mathrm{X}^{+}}^{\mathrm{o}}} \sqrt{\frac{D_{\mathrm{A}}^{\mathrm{o}}}{D_{\mathrm{X}^{+}}^{\mathrm{w}}}}\right)+E_{\mathrm{ref} 1}^{\circ}-E_{\mathrm{ref} 2}^{\circ}
$$

Then the formal ion transfer potential $\Delta_{\mathrm{w}}^{\mathrm{o}} \phi_{\mathrm{X}^{+}}^{\circ 1}$ is calculated by equation SI 19 ,

$$
\Delta_{\mathrm{w}}^{\mathrm{o}} \phi_{\mathrm{X}^{+}}^{\circ}=\Delta E_{1 / 2}-\frac{R T}{F} \ln \left(\frac{c_{\mathrm{A}}^{\mathrm{o}, 0}}{c_{\mathrm{X}^{+}}^{\mathrm{o}}} \sqrt{\frac{D_{\mathrm{A}}^{\mathrm{o}}}{D_{\mathrm{X}^{+}}^{\mathrm{w}}}}\right)-E_{\mathrm{ref} 1}^{\circ}+E_{\mathrm{ref} 2}^{\circ}
$$

In this work, we employed potential-step chronoamperometry at different potentials to determine the steady-state current and build the $i-E$ curve; this yielded the half-wave potential, $E_{1(1 / 2)}$, for the complete process of electron and ion transfer. $E_{2(1 / 2)}$ is measured and shown in Figure 2. $E_{\mathrm{ref} 1}^{\circ}$ and $E_{\mathrm{ref} 2}^{\circ}$ can be obtained by $\mathrm{CV}$ correction for the well-defined redox 
reactions on the UME in aqueous and oil phases, respectively (shown below). Finally, $\Delta_{\mathrm{w}}^{\mathrm{o}} \phi_{\mathrm{X}^{+}}^{\circ}$ can be estimated.

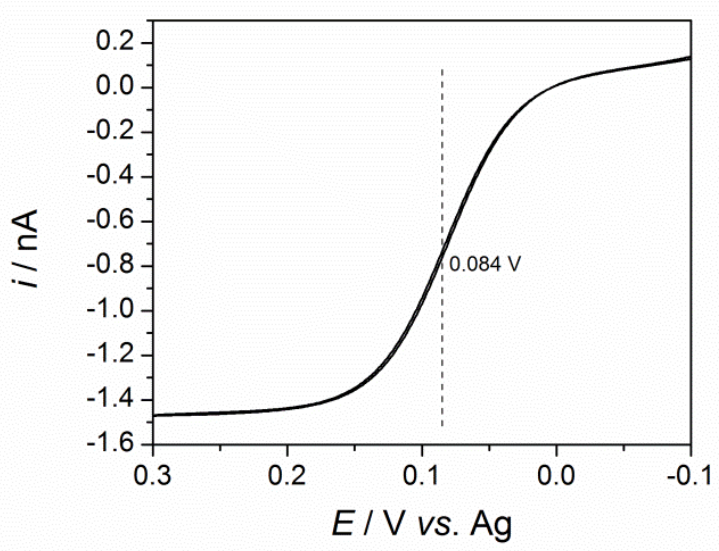

Figure S3. $\mathrm{CV}$ of $1 \mathrm{mM} \mathrm{FcMeOH}+100 \mathrm{mM} \mathrm{KNO}_{3}$ in aqueous on the Pt UME $(10 \mu \mathrm{m}$ in diameter) at a scan rate of $10 \mathrm{mV} \mathrm{s}^{-1}$. A Pt wire is the counter electrode and a $\mathrm{Ag}$ wire as the quasi-reference electrode.

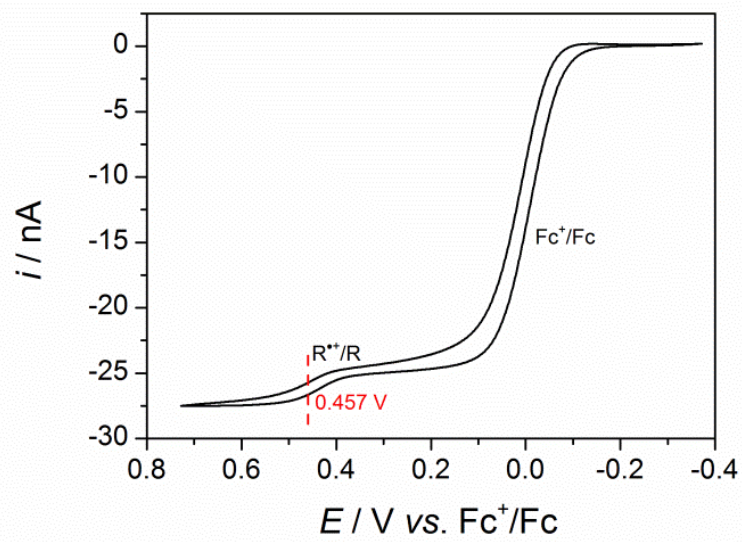

Figure S4. CV of $5 \mathrm{mM}$ ferrocene $(\mathrm{Fc})+2.5 \mathrm{mM}$ rubrene $+400 \mathrm{mM}$ IL-PA in toluene on the Pt UME $(25 \mu \mathrm{m}$ in diameter) at a scan rate of $10 \mathrm{mV} \mathrm{s}^{-1}$. A Pt wire is the counter electrode and a $\mathrm{Ag}$ wire as the quasi-reference electrode.

Estimation of Standard/Formal Redox Potential of Rubrene in Toluene with respect to Aqueous Standard Hydrogen Electrode (SHE)

Generally, a half redox reaction of $\mathrm{O}$ to $\mathrm{R}$ in phase $\alpha$ can be expressed in equation shown below,

$\mathrm{O}(\alpha)+n \mathrm{e}^{-} \leftrightarrow \mathrm{R}(\alpha)$

with the standard redox potential in the aqueous standard hydrogen electrode (SHE) scale expressed as:

$$
\left[E_{\mathrm{O} / \mathrm{R}}^{\circ}\right]_{\mathrm{SHE}}^{\alpha}=\frac{\Delta G^{\circ}}{-n F}=\frac{1}{n F}\left[\mu_{\mathrm{O}}^{\circ, \alpha}-\mu_{\mathrm{R}}^{\circ, \alpha}-n\left(\mu_{\mathrm{H}^{+}}^{\circ, \mathrm{w}}-\frac{1}{2} \mu_{\mathrm{H}_{2}}^{\circ, \mathrm{w}}\right)\right]
$$


where $\Delta G^{\circ}$ is the standard Gibbs free energy change, $\mu_{i}^{\circ}{ }^{\alpha}$ is the standard electrochemical potential of the participating species $-i$ in its respective phase $(\alpha$, i.e. toluene or aqueous $-\mathrm{w})$. Hence the standard redox potentials of the reaction (SI 20) in toluene and aqueous are:

$$
\begin{aligned}
& {\left[E_{\mathrm{O} / \mathrm{R}}^{\circ}\right]_{\mathrm{SHE}}^{\text {toluene }}=\frac{1}{n F}\left[\mu_{\mathrm{O}}^{\circ \text {,toluene }}-\mu_{\mathrm{R}}^{\circ \text {,toluene }}-n\left(\mu_{\mathrm{H}^{+}}^{\circ, \mathrm{w}}-\frac{1}{2} \mu_{\mathrm{H}_{2}}^{\circ, \mathrm{w}}\right)\right]} \\
& {\left[E_{\mathrm{O} / \mathrm{R}}^{\circ}\right]_{\mathrm{SHE}}^{\mathrm{w}}=\frac{1}{n F}\left[\mu_{\mathrm{O}}^{\circ, \mathrm{w}}-\mu_{\mathrm{R}}^{\circ, \mathrm{w}}-n\left(\mu_{\mathrm{H}^{+}}^{\circ, \mathrm{w}}-\frac{1}{2} \mu_{\mathrm{H}_{2}}^{\circ, \mathrm{w}}\right)\right]}
\end{aligned}
$$

If equation SI 22 is subtracted by equation SI 23, then the standard redox potential of the reaction SI 20 in toluene in the aqueous SHE scale is,

$$
\begin{aligned}
& {\left[E_{\mathrm{O} / \mathrm{R}}^{\circ}\right]_{\mathrm{SHE}}^{\text {toluene }}=\left[E_{\mathrm{O} / \mathrm{R}}^{\circ}\right]_{\mathrm{SHE}}^{\mathrm{w}}+\frac{1}{n F}\left[\mu_{\mathrm{O}}^{\circ \text {,toluene }}-\mu_{\mathrm{O}}^{\circ}, \mathrm{w}+\mu_{\mathrm{R}}^{\circ}, \mathrm{w}-\mu_{\mathrm{R}}^{\circ}, \text { toluene }\right]} \\
& =\left[E_{\mathrm{O} / \mathrm{R}}^{\circ}\right]_{\mathrm{SHE}}^{\mathrm{w}}+\frac{1}{n F}\left(\Delta G_{\mathrm{O}}^{\circ, \mathrm{w} \rightarrow \text { toluene }}-\Delta G_{\mathrm{R}}^{\circ, \mathrm{w} \rightarrow \text { toluene }}\right)
\end{aligned}
$$

where $\Delta G_{i}^{\circ}$, w $\rightarrow$ toluene is the standard Gibbs transfer energy of species $i$ from the aqueous to toluene phase.

For the case of inner reference reaction $\mathrm{Fc}^{+}+\mathrm{e}^{-} \leftrightarrow \mathrm{Fc}\left[E_{\mathrm{Fc}^{+} / \mathrm{Fc}}^{\circ}\right]_{\mathrm{SHE}}^{\mathrm{w}}=0.381 \mathrm{~V}^{9}$

$$
\left[E_{\mathrm{Fc}^{+} / \mathrm{Fc}}^{\circ}\right]_{\mathrm{SHE}}^{\text {toluene }}=\left[E_{\mathrm{Fc}^{+} / \mathrm{Fc}}^{\circ}\right]_{\mathrm{SHE}}^{\mathrm{w}}+\frac{1}{F}\left(\Delta G_{\mathrm{Fc}^{+}}^{\circ, \mathrm{w} \rightarrow \text { toluene }}-\Delta G_{\mathrm{Fc}}^{\circ, \mathrm{w} \rightarrow \text { toluene }}\right)
$$

where $\Delta G_{\mathrm{Fc}}^{\circ, \mathrm{w} \rightarrow \text { toluene }}=-2.303 R T \log P_{\mathrm{Fc}}^{\circ}$ and $\log P_{\mathrm{Fc}}^{\circ}$ is the logarithm of standard toluene/water partition coefficient of $\mathrm{Fc}$ with the reported value of $4.440 .{ }^{10}$

Hence $\Delta G_{\mathrm{Fc}}^{\circ, \mathrm{w} \rightarrow \text { toluene }}=-25.35 \mathrm{~kJ} \mathrm{~mol}^{-1}$

While $\Delta G_{\mathrm{Fc}^{+}}^{\circ, \mathrm{w} \rightarrow \text { toluene }}$ can be calculated using equation SI 28 shown below,

$$
\begin{aligned}
\Delta G_{\mathrm{Fc}^{+}}^{\circ, \mathrm{w} \rightarrow \text { toluene }} & =\Delta G_{\mathrm{Fc}^{+}}^{\circ, \mathrm{W} \rightarrow \text { toluene }}(\text { charge dependent }) \\
& +\Delta G_{\mathrm{Fc}^{+}}^{\circ, \mathrm{w} \rightarrow \text { toluene }}(\text { charge independent })
\end{aligned}
$$

in which $\Delta G_{\mathrm{Fc}^{+}}^{\circ} \mathrm{w} \rightarrow$ toluene $($ charge dependent)can be estimated using the classical electrostatic solvation model of Born, ${ }^{11}$

$\Delta G_{\mathrm{Fc}^{+}}^{\circ, \mathrm{w} \rightarrow \text { toluene }}($ charge dependent $)=\frac{N_{\mathrm{A}} z^{2} \mathrm{e}^{2}}{8 \pi \varepsilon_{0} r_{\mathrm{Fc}^{+}}}\left(\frac{1}{\varepsilon_{\text {toluene }}}-\frac{1}{\varepsilon_{\mathrm{w}}}\right)$ 
where e is the elementary charge, $z$ is the charge number of $\mathrm{Fc}^{+}$with the sign $(+1), \varepsilon_{0}$ is the permittivity of vacuum, and $\varepsilon_{\text {toluene }}$ and $\varepsilon_{\mathrm{w}}$ are the dielectric constant (relative permittivity) of toluene and water phase, respectively taken as $2.38^{12}$ and $78.54 .{ }^{13}$ The radius of $\mathrm{Fc}^{+}\left(r_{\mathrm{Fc}^{+}}\right)$is taken as the same value of $\mathrm{Fc}$ with a crystallographic radius of $0.365 \mathrm{~nm}^{14}$ So $\Delta G_{\mathrm{Fc}^{+}}^{\circ \text {, } \rightarrow \text { toluene }}($ charge dependent $)=77.50 \mathrm{~kJ} \mathrm{~mol}^{-1}$.

For evaluating $\Delta G_{\mathrm{Fc}^{+}}^{\circ, \mathrm{w} \rightarrow \text { toluene }}$ (charge independent) , it is equivalent to

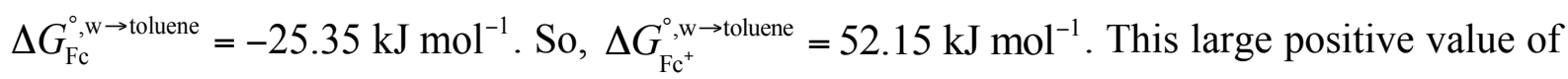
$\Delta G_{\mathrm{Fc}^{+}}^{\circ, \mathrm{w} \rightarrow \text { toluene }}$ indicates it is very easy to transfer $\mathrm{Fc}^{+}$after $\mathrm{Fc}$ oxidation from toluene to water, as has been observed in the single toluene $(\mathrm{Fc})$ droplet collision electrochemical measurement. $^{2}$

Finally, $\left[E_{\mathrm{Fc}^{+} / \mathrm{Fc}}^{\circ}\right]_{\mathrm{SHE}}^{\text {toluene }}=0.381+\frac{1}{F}\left(\Delta G_{\mathrm{Fc}^{+}}^{\circ, \mathrm{w} \rightarrow \text { toluene }}-\Delta G_{\mathrm{Fc}}^{\circ, \mathrm{w} \rightarrow \text { toluene }}\right)=1.184 \mathrm{~V}$

Therefore, the standard/formal redox potential of rubrene $(\mathrm{R})$ in toluene with respect to aqueous SHE is,

$\left[E_{\mathrm{R}^{\circ+} / \mathrm{R}}^{\circ}\right]_{\mathrm{SHE}}^{\text {toluene }}=1.184+0.457=1.641 \mathrm{~V}$

considering the half-wave potential difference between $\mathrm{R}^{+} / \mathrm{R}$ and $\mathrm{Fc}^{+} / \mathrm{Fc}$ is $0.457 \mathrm{~V}$ shown in Figure S4. 

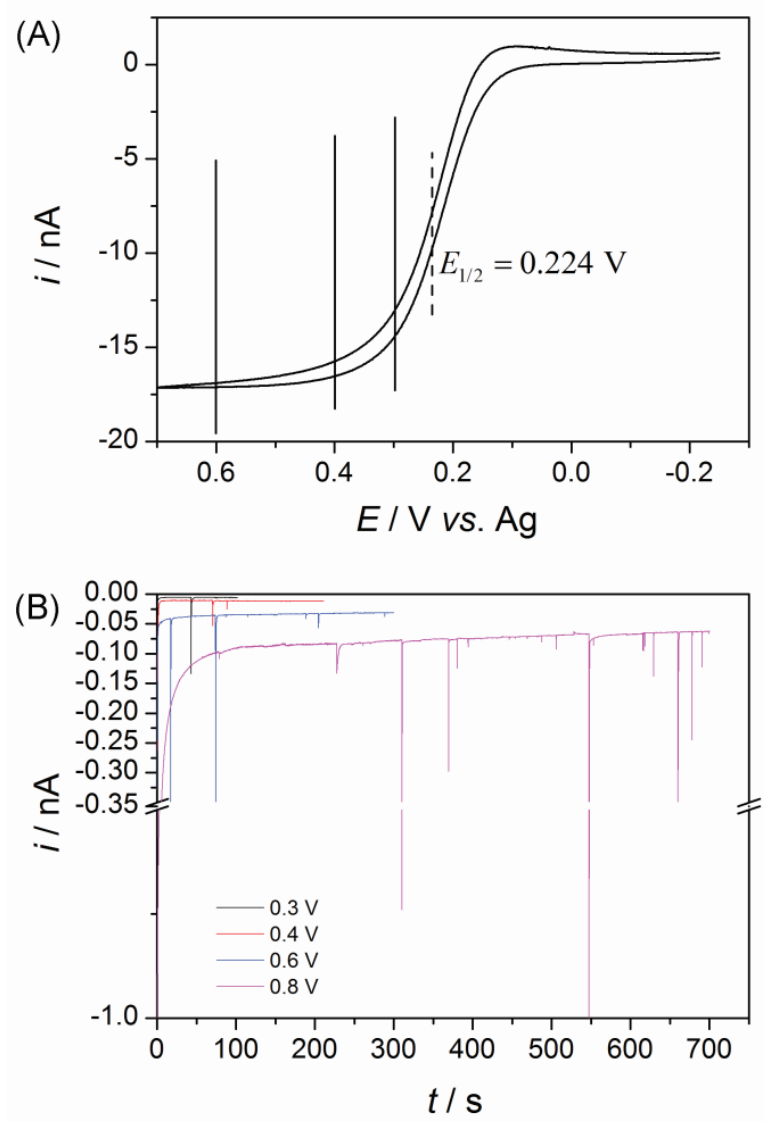

Figure S5. (A) CV of $15 \mathrm{mM}$ DEC + $400 \mathrm{mM}$ IL-PA in toluene on the Pt UME $(25 \mu \mathrm{m}$ in diameter $)$ at a scan rate of $10 \mathrm{mV} \mathrm{s}^{-1}$. A Pt wire is served as the counter electrode, and with a $\mathrm{Ag}$ wire as the quasi-reference electrode. (B) Amperometric $i-t$ curves of collisions of the emulsion toluene droplets (15 mM DEC $+400 \mathrm{mM}$ IL-PA) in water on the Pt UME biased at different potentials vs. Ag wire. The concentrations of the emulsion droplets for collision experiments were diluted 5 times using Millipore water from the originally-prepared emulsion. Due to the poly-dispersity of this emulsion and hence the uncertainty in the average droplet size measured by DLS, the concentration was not specified herein.

\section{References}

(1) Xiao, X.; Bard, A. J. J. Am. Chem. Soc. 2007, 129, 9610-9612.

(2) Kim, B.-K.; Boika, A.; Kim, J.; Dick, J. E.; Bard, A. J. J. Am. Chem. Soc. 2014, 136, 4849-

4852.

(3) Kim, B.-K.; Kim, J.; Bard, A. J. J. Am. Chem. Soc. 2015, 137, 2343-2349.

(4) Li, Y.; Deng, H.; Dick, J. E.; Bard, A. J. Anal. Chem. 2015, 87, 11013-11021.

(5) Zhou, M.; Gan, S.; Zhong, L.; Su, B.; Niu, L. Anal. Chem. 2010, 82, 7857-7860.

(6) Bard, A. J.; Faulkner, L. R. Electrochemical Methods; 2nd ed.; John Wiley \& Sons: New

York, 2001.

(7) Monroe, C. W.; Daikhin, L. I.; Urbakh, M.; Kornyshev, A. A. Phys. Rev. Lett. 2006, 97, 136102.

(8) Scholz, F. Annu. Rep. Prog. Chem., Sect. C: Phys. Chem. 2006, 102, 43-70.

(9) Daniele, S.; Baldo, M. A.; Bragato, C. Electrochem. Commun. 1999, 1, 37-41.

(10) Abraham, M. H.; Benjelloun-Dakhama, N.; Gola, J. M. R.; Acree, J. W. E.; Cain, W. S.; Enrique Cometto-Muniz, J. New J. Chem. 2000, 24, 825-829.

(11) Osakai, T.; Ebina, K. J. Phys. Chem. B 1998, 102, 5691-5698.

(12) Moumouzias, G.; Ritzoulis, G. J. Chem. Eng. Data 1997, 42, 710-713. 
(13) Osakai, T.; Ebina, K. In Liquid Interfaces in Chemical, Biological and Pharmaceutical Applications; Volkov, A., G., Ed.; Marcel Dekker: New York, 2001; Vol. 95; pp 27-62.

(14) Tsierkezos, N. G.; Ritter, U. J. Appl. Electrochem. 2010, 40, 409-417. 